\title{
ORIGINAL RESEARCH

ELECTROMYOGRAPHIC ACTIVITY OF THE VASTUS MEDIALIS
OBLIQUE AND VASTUS LATERALIS DURING MAXIMUM
VOLUNTARY ISOMETRICS IN DIFFERENT WEIGHT BEARING
POSITIONS OF THE FOOT

\author{
Sreekar Kumar Reddy . ${ }^{1}$ \\ B. Siva kumar ${ }^{2}$ \\ N. Vamsidhar ${ }^{2}$ \\ G. Haribabu ${ }^{3}$
}

\section{ABSTRACT}

Background: Patellofemoral pain syndrome is a very common disorder. $90 \%$ of the general population has some degree of pathologic changes of the patellofemoral joint. Knowledge regarding the cause and prevention of patellofemoral pain syndrome is essential. Therefore the purpose of this study is intended to know whether different foot positions alter Vastus Medialis Oblique and Vastus Lateralis that leads to dysfunctions of knee joint.

Method: 30 subjects are included in study and investigated foot in different foot positions are in neutral, pronated and supinated foot positions and performed maximum voluntary isometric contractions are recorded with electromyography.

Results: EMG amplitudes (microvolts) of VL and VMO at three different weight bearing positions of foot during maximum voluntary contraction analysis by using one-way Analysis of Variance. Mean amplitudes of foot positions in pronation shown significant difference while comparing with neutral and supination.

Conclusion: The VMO and VL activity shows significant difference in the pronated foot weight bearing position compared to the neutral and supinated foot. Performing the maximum voluntary isometric contractions of VMO and VL with pronated foot elicited significantly higher EMG activity compared to Neutral or supinated weight bearing positions of foot. The results of this study also suggested that for patellofemoral pain which is caused by pronated foot can be treat with by using the soft foot orthoses.

Keywords: electromyography, vastus medialis oblique, vatus lateralis, isometrics

Received $26^{\text {th }}$ June 2014, revised $18^{\text {th }}$ July 2014, accepted 21 ${ }^{\text {st }}$ July 2014

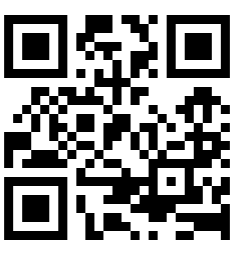

DOI: 10.15621/ijphy/2014/v1i3/53465

www.ijphy.org

\footnotetext{
${ }^{2}$ Assistant Professor, Narayana College of Physiotherapy, Nellore. e-mail: skumarphysio@gmail.com

${ }^{2}$ Assistant Professor, Narayana College of Physiotherapy, Nellore. e-mail: nvamsin@gmail.com

${ }^{3}$ Assistant Professor, Narayana College of Physiotherapy,

Nellore.e-mail: hari9885864899@gmail.com
}

\section{CORRESPONDING AUTHOR}

\author{
${ }^{1}$ Sreekar Kumar Reddy .R \\ Professor, Narayana College of \\ Physiotherapy, Nellore. \\ e-mail: sreekarpt@yahoo.co.in
}




\section{INTRODUCTION}

Patellofemoral pain syndrome is a very common disorder. $90 \%$ of the general population has some degree of pathologic changes of the patellofemoral joint $^{1}$. Knowledge regarding the cause and prevention of patellofemoral pain syndrome is essential. The most common complaint of patients with patellofemoral pain syndrome is dull, aching pain in the anterior aspect of knee. Many factors may be related to the development of patellofemoral syndrome: a direct blow to the patella, abnormal anatomic factors such as genu valgus, structural abnormalities and patellofemoral malalignment. Patellofemoral malalignment is including improper patella tracking, has been suggested as the primary cause of patellofemoral pain syndrome. Abnormal foot position has been suggested as an important factor that may lead to patellofemoral malalignment. Abnormal foot pronation and subsequent rotation of the lower extremity has been hypothesized as a being contributory to patellofemoral pain ${ }^{2}$. The important contributory muscles are Vastus Medialis Oblique and Vastus Lateralis. VMO is the dynamic medial stabilizer of the patella. It originates from the medial lip of linea aspera of femur. The fibers of VMO insert into the patella at an angle of 50-55 degrees from the vertical axis ${ }^{3}$. Vastus Lateralis is the lateral stabilizer of the patella. It originates by a thin aponeurosis and from the lateral lip of the linea aspera of femur. The fibers of VL oriented $15^{\circ}$ to the vertical axis and insert into patella ${ }^{4}$. Vastus Medialis is considered to be a key muscle in knee extension and patellar stability and to be the only muscle which directly and actively counteracts lateral movement of the patella ${ }^{5}$. Vastus Medialis is the primary muscle contributor to the overall medial force vector and the Vastus Lateralis is the primary muscle contributor to the overall lateral force vector. Full extension of the knee could not be completed without the vasti muscles especially the Vastus Medialis. Vastus Medialis is the first muscle of the quadriceps group to atrophy and that it responds to rehabilitation more slowly than the vastus lateralis, causing it to exert less force on the patella. This imbalance can cause patellar tracking dysfunction ${ }^{6}$. Weight bearing supination of subtalar joint results in motion of both the calcaneus and talus. The calcaneus inverts and the talus simultaneously abducts and dorsiflexes relative to calcaneus. The leg rotates laterally. The dorsi flexion of talus on calcaneus causes a slight extension motion to knee. Weight bearing pronation of subtalar joint results in eversion of calcaneus, the talus adducts and plantar flexes relative to the calcaneus. The leg rotates medially. The plantar flexion of talus on calcaneus causes proximal aspect of tibia moves forward to flex the knee slightly ${ }^{7}$. The movement of pronation has components of motion in all three cardinal planes eversion, adduction and dorsiflexion of foot. As pronation occurs, the eversion of subtalar joint causes internal tibial rotation ${ }^{8}$. The tibia internally rotates with the talus due to tight articulation of the ankle joint mortice ${ }^{9}$. Excessive subtalar joint pronation is one abnormality that has been suggested to contribute to the pathomechanics of patellofemoral pain ${ }^{10}$. Once a subject bears weight on a pronated foot, the tibia rotates internally. The influence of this internally rotated tibia on the quadriceps angle and medial or lateral force balance is unclear. Excessive subtalar pronation during stance phase can alter the normal rotation of tibia in frontal and transverse planes as a result of the anatomical congruency of the talus within the ankle mortice ${ }^{11}$. Structural abnormalities of the foot are believed to be one of the primary causes of excessive subtalar joint pronation. Hyper pronation of subtalar joint significantly alters knee joint rotation, laxity and bio-mechanical function ${ }^{12}$. When the subject is in a weight bearing position with a pronated foot, the tibial tubercle will shift more medially and also pull the patella medially. Prolonged foot pronation can cause internal rotation of femur and then create an abnormal quadriceps pull on the patella. The internal rotation of the lower extremity resulting from subtalar joint pronation serves to increase Q-angle and the lateral component of the quadriceps Vector.

Internal tibial rotation is thought to increase joint laxity and create a pre loading rotatory stress to the knee joint during weight bearing activities. The foot position may have a mechanical effect on patellofemoral joint function. Foot position could have a direct impact on the quadriceps force vector. Rear foot varus has been reported to be the most common structural deformity. Excessive pronation will delay the external rotation of tibia which normally accompanies subtalar joint supination. A number of studies have been performed which indicates that the levels of activity of the quadriceps muscles can be affected by the angle of knee or position of foot. The patellofemoral subjects demonstrating a higher range of rear foot varus, indicating some patients may have been more predisposed to patellofemoral pain than others. Electromyography is an appropriate tool to measure the relative intensity of muscle activity occurring during exercises or functional activities ${ }^{13}$. Over the past two decades, a 
number of researchers have been interested in comparison of the Electromyographic activity of Vastus Medialis Oblique and Vastus Lateralis muscles during physical exercise and different activities. One of the primary reasons for this interest is that muscle imbalance between these muscles lead to various knee disorders especially patellofemoral syndrome. Surface electromyographic activity was found to be greatest for the Vastus Lateralis followed by Vastus Medialis and least for the Rectus Femoris ${ }^{14}$. EMG recordings from the rectus femoris, vastus lateralis and vastus medialis muscles during SLR and Isometrics. Their data revealed that quadriceps femoris muscle activity was greater during isometric contractions ${ }^{15}$. External rotation of the leg produced highest level of electrical activity in the vastus medialis, while internal produced the highest level of activity in Vastus Lateralis. An internally rotated foot position produces significantly higher electromyographical activity than an externally rotated foot position for both the Vastus medialis and Vastus lateralis. To limit pronation, it is common practice to prescribe inshoe foot orthoses with a varus correction. This is presumed to reduce internal rotation of tibia and to have some effect on the internal-external rotation patterns of the tibiofemoral joint with alleviations of stresses on the lateral aspect of the knee and improvement of the tracking of patella. Statistically significant change in patellar positioning (medial glide) after placement of semi rigid posting ${ }^{16}$. No increase in VMO EMG in neither maximal supination nor maximal pronation of the subtalar joint produces a resultant increase in EMG activity of VMO during exercise ${ }^{17}$. Several authors have suggested different conclusions. Some says that there is no difference between the foot positions on VMO \& VL activities, some authors says that foot positions may have impact on the muscles. The tibia may start to rotate internally or externally when a subject bears weight on a pronated or a supinated foot. Therefore the purpose of this study is intended to know whether different foot positions alter Vastus Medialis Oblique and Vastus Lateralis that leads to dysfunctions of knee joint.

\section{METHODS}

Samples are selected with Simple Random Sampling, The test sample consists of 30 volunteers with age group of 18-25 years were selected from narayana college of physiotherapy, Nellore. The purpose of the study was explained to all the subjects. An informed consent was taken, followed by demographic data from each subjects. Study design used in Simple Experimental Design. Subjects capable of understanding the instructions given by the therapist. Subjects are excluded are patellofemoral pain, surgical history of lower extremity, neuro muscular disorders, fixed deformities of lower extremities. Subjects were requested to attend the testing session with clean shave over the right VMO and VL in leisure wear and shorts. Explained and demonstrated the procedure to the subjects. The skin over the Vastus Medialis oblique and Vastus Lateralis was cleaned with spirit and cotton wool, in order to remove dead epidermis and oil as well as to reduce the skin impedance. Electrodes with conductivity gel applied were fixed on the skin using straps. The electrodes were placed for right Vastus Medialis Oblique, over the muscle belly approximately $4 \mathrm{~cm}$ superior and $3 \mathrm{~cm}$ medial to superomedial patellar border and oriented $55^{\circ}$ to the vertical. For right Vastus Lateralis, $10 \mathrm{~cm}$ superior and 6 to $8 \mathrm{~cm}$ lateral to the superior border of the patella and oriented $15^{0}$ to the vertical. Ground electrode were placed over the fibular head and inter electrode distance was $22 \mathrm{~mm}$. Subjects were asked to perform maximum voluntary isometrics contractions of Vastus Medialis Oblique in standing position, the foot position was in neutral. They were asked to hold the contraction for 4 secs and recorded the activity of the muscle in Electromyographic machine in the form of AMPLITUDE. They were then asked to perform this Exercise for 3 times. After that placed a $10^{\circ}$ of medial wedge beneath the foot in order to achieve supination. The foot placed over the wooden wedge like the lateral border of foot was placed over the thinner edge of wooden wedge and the medial border was placed over the thickest edge. They were asked to perform the maximum voluntary contractions and recorded the electromyographic activity for 3 times with the interval of 30 secs rest period. They were asked to relax for 2 mins to recovery period of the muscle. After that placed a $10^{\circ}$ of lateral wedge beneath the foot in order to achieve pronation. The foot was placed over the wooden wedge like medial border of foot was placed over the thinner edge of wood and the lateral border was placed over the thickest part. They were asked to perform the maximum voluntary isometric contractions and recorded the electromyographic activity for 3 times with the interval of 30 secs rest period. The data was documented in recording tool. Same procedure was performed for the Vastus Lateralis muscle. Subjects were asked the maximum voluntary isometrics contractions in neutral position, with the medial wedge (supination of foot) and with the lateral wedge (pronation of foot). The electromyographic activity of the Vastus Lateralis was recorded and documented in the recording tool. Each subject 
therefore was required to perform a series of 18 maximum voluntary isometric contractions with different weight bearing positions of foot to eliminate the order effect.

\section{RESULTS}

Table 1: EMG amplitudes (microvolts) of VL at three different weight bearing positions of foot during maximum voluntary contraction analysis by using one-way Analysis of Variance.

\begin{tabular}{|c|c|c|c|}
\hline Foot position & $\begin{array}{c}\text { Mean } \\
\text { Amplitude }\end{array}$ & $\begin{array}{c}\text { Standard } \\
\text { deviation }\end{array}$ & p-value \\
\hline Neutral & 356.87 & 85.28 & $\begin{array}{c}0.013 \\
\text { Significant } \\
(<0.05)\end{array}$ \\
\hline $\begin{array}{c}\text { Supination } \\
\text { (Medial wedge) }\end{array}$ & 363.00 & 73.75 & 75.90 \\
\hline $\begin{array}{c}\text { Pronation } \\
\text { (lateral Wedge) }\end{array}$ & 412.50 & 7 & \\
\hline
\end{tabular}

Table 2: EMG amplitudes (micrvolts) of VMO at three different weight bearing positions of foot during maximum voluntary contractions analysis by using one-way Analysis of Variance.

\begin{tabular}{|c|c|c|c|}
\hline Foot position & $\begin{array}{c}\text { Mean } \\
\text { Amplitude }\end{array}$ & $\begin{array}{l}\text { Standard } \\
\text { deviation }\end{array}$ & p-value \\
\hline Neutral & 377.11 & 90.20 & \multirow{3}{*}{$\begin{array}{c}0.042 \\
\text { Significant } \\
(<0.05)\end{array}$} \\
\hline $\begin{array}{c}\text { Supination } \\
\text { (Medial wedge) }\end{array}$ & 349.79 & 80.44 & \\
\hline $\begin{array}{c}\text { Pronation } \\
\text { (lateral Wedge) }\end{array}$ & 401.55 & 71.99 & \\
\hline
\end{tabular}

Table 3: Comparison of VL activity between Neutral and Supination (medial wedge) positions of foot during maximum voluntary isometrics contractions by using two-tailed paired 't'-test.

\begin{tabular}{|c|c|c|c|c|c|}
\hline Foot position & $\begin{array}{c}\text { Mean } \\
\text { amplitude }\end{array}$ & $\begin{array}{l}\text { Standard } \\
\text { deviation }\end{array}$ & $\begin{array}{c}\text { SE } \\
\text { Mean }\end{array}$ & $\begin{array}{c}\text { t- } \\
\text { value }\end{array}$ & p-value \\
\hline Neutral & 356.9 & 85.3 & 16 & \multirow{2}{*}{0.30} & \multirow{2}{*}{$\begin{array}{l}0.77 \text { Not } \\
\text { significant } \\
(>0.05)\end{array}$} \\
\hline $\begin{array}{c}\text { Supination } \\
\text { (Medial wedge) }\end{array}$ & 363.0 & 73.7 & 13 & & \\
\hline
\end{tabular}

Table 4: Comparison of VL activity between Neutral and Pronation (lateral wedge) positions of foot during maximum voluntary isometrics contractions by using two tailed paired ' $t$ ' - test.

\begin{tabular}{|c|c|c|c|c|c|}
\hline Foot position & $\begin{array}{c}\text { Mean } \\
\text { amplitude }\end{array}$ & $\begin{array}{c}\text { Standard } \\
\text { deviation }\end{array}$ & $\begin{array}{c}\text { SE } \\
\text { Mean }\end{array}$ & $\begin{array}{c}\text { t- } \\
\text { value }\end{array}$ & p-value \\
\hline Neutral & 356.9 & 85.3 & 16 & & $\begin{array}{c}0.0099 \\
\text { significant } \\
\left(\begin{array}{c}\text { Pronation } \\
\text { (Lateral wedge) }\end{array}\right.\end{array}$ \\
\hline
\end{tabular}

Table 5: Comparison of VMO activity between Neutral and Supination (medial wedge) position of foot during maximum voluntary isometrics contractions by using two tailed paired ' $\mathrm{t}$ ' - test.

\begin{tabular}{|c|c|c|c|c|c|}
\hline Foot position & $\begin{array}{c}\text { Mean } \\
\text { amplitude }\end{array}$ & $\begin{array}{c}\text { Standard } \\
\text { deviation }\end{array}$ & $\begin{array}{c}\text { SE } \\
\text { Mean }\end{array}$ & $\begin{array}{c}\text { t- } \\
\text { value }\end{array}$ & p-value \\
\hline Neutral & 377.1 & 90.2 & 16 & & 0.19 Not \\
\hline $\begin{array}{c}\text { Supination } \\
\text { (Medial wedge) }\end{array}$ & 347.8 & 80.4 & 15 & & $\begin{array}{c}\text { significant } \\
(>0.05)\end{array}$ \\
\hline
\end{tabular}


Table 6: Comparison of VMO activity between Neutral and Pronation (lateral wedge) positions of foot during maximum voluntary isometrics contractions by using two-tailed paired 't'-test.

\begin{tabular}{|c|c|c|c|c|c|}
\hline Foot position & $\begin{array}{c}\text { Mean } \\
\text { amplitude }\end{array}$ & $\begin{array}{c}\text { Standard } \\
\text { deviation }\end{array}$ & $\begin{array}{c}\text { SE } \\
\text { Mean }\end{array}$ & $\begin{array}{c}\text { t- } \\
\text { value }\end{array}$ & p-value \\
\hline Neutral & 377.1 & 90.2 & 16 & & $0.25 \mathrm{Not}$ \\
\hline $\begin{array}{c}\text { Pronation } \\
\text { (Lateral wedge) }\end{array}$ & 401.6 & 72.0 & 13 & & $\begin{array}{c}\text { significant } \\
(>0.05)\end{array}$ \\
\hline
\end{tabular}

GRAPH 1: Shows Vatus Lateralis activity in different weight bearing positions of foot

ELECTROMYOGRAPHIC ACTIVITY OF VL
IN DIFFERENT WEIGHT BEARING POSITIONS OF FOOT

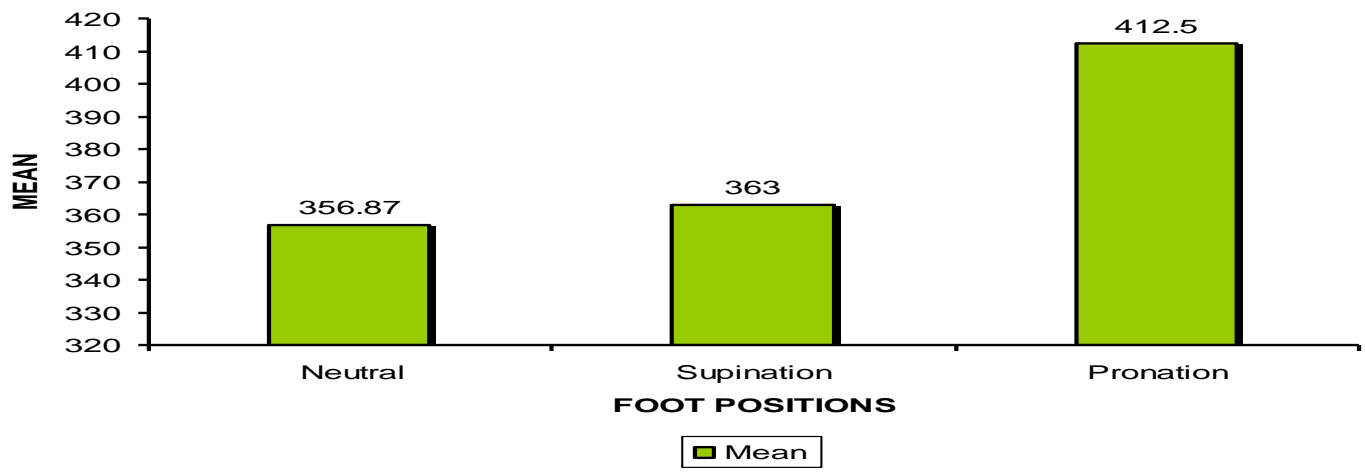

GRAPH 2: Shows Vatus Medialis oblique activity in different weight bearing positions of foot

\section{ELECTROMYOGRAPHIC ACTIVITY OF VMO IN DIFFERENT WEIGHT BEARING POSITIONS OF FOOT}

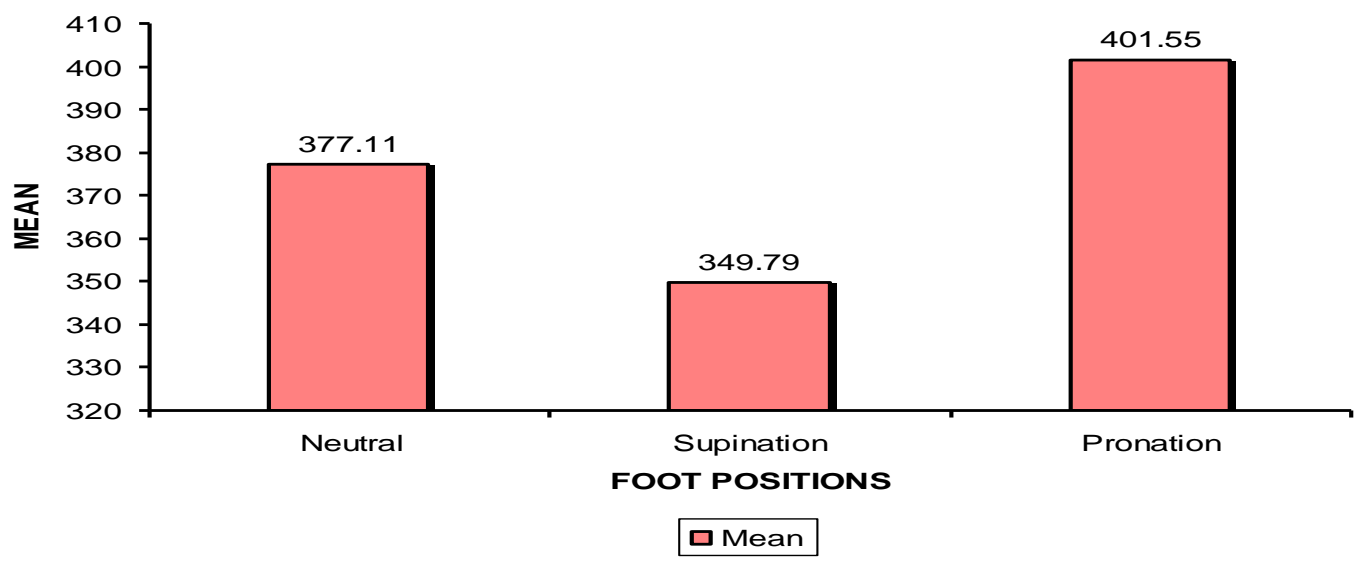

\section{DISCUSSION}

The results indicated that maximum voluntary isometric contractions of VMO \& VL shown significant difference $(\mathrm{P}<0.05)$ in pronated (lateral wedge) foot. One explanation for this finding may be that weight bearing pronation of subtalar joint results in eversion of calcaneus, the talus adducts and plantar flexes relative to the calcaneus. The plantar flexion of talus on calcaneus causes proximal aspect of tibia moves forward to flex the knee slightly. This knee flexion may be the cause for significant difference while performing the maximum voluntary isometric contractions. Once a subject bears weight on a pronated foot, the tibia rotates internally; this serves to increase Q-angle and lateral component of the quadriceps vector. This internal rotation also creates a pre loading rotatory stress to the knee joint during weight bearing activities. A number of studies have been performed which indicates that the levels of activity of the quadriceps muscles can be affected by the angle of knee or position of foot. The foot position may have a impact of mechanical effect on patellofemoral joint function. Foot position could have a direct impact on the quadriceps force rector. Increased rear foot varus may be a contributing factor in patellofemoral pain and should be assessed when evaluating the events at the subtalar joint and the lower extremity. Results shown that VL activity is more than the VMO activity, compared to the pronated foot with the neutral and supinated foot. This can be because 
weight bearing position with a pronated foot, the tibial tubercle will shift more medially and also pull the patella medially. This patellar movement may cause stretch on Vastus Lateralis muscle providing optimal length tension relationship, this may be the cause for more VL activity than VMO in pronated foot. Stated that there is no increase in VMO EMG activity neither in maximal supination nor maximal pronation of the subtalar joint produces a resultant increase in EMG activity of VMO during exercise, concluded that foot position may not have a significant effect on Quadriceps muscle activity. External rotation of the leg produced highest level of electrical activity in the Vastus Medialis, while internal rotation produced the highest level of activity in the Vastus Lateralis. In this an internally rotated foot position produces significantly higher electromyographical activity than an externally rotated foot position for both the Vastus Medialis and Vastus Lateralis. Excessive subtalar pronation during the stance phase can alter the normal rotation of tibia in the frontal and transverse planes as a result of the anatomical congruency of the talus within the ankle mortice. A weakened VM could predispose one to tibiofemoral and patellofemoral dysfunction. Internal tibial rotation is thought to increase joint laxity and create a preloading rotatory stress to the knee joint during weight bearing activities. A number of studies have been performed which indicates that the levels of activity of the quadriceps muscles can be affected by the angle of knee or position of foot. The patellofemoral subjects demonstrating a higher range of rear foot varus, indicating some patients may have been more predisposed to patellofemoral pain than others. Patellofemoral pain is caused by a variety of factors including structural abnormalities like abnormal foot position is an important factor that may lead to patellofemoral malalignment. This patellofemoral malalignment leads to patellofemoral pain syndrome. The VMO and VL muscles imbalance activity can lead to the patellofemoral malalignment. Several researchers have suggested to use of isometric quadriceps exercises to treat patellofemoral pain syndrome. There is a statistically significant change in patellar positioning (medial glide) after placement of semi rigid posting. This suggested that the semi rigid material can alter the patellar tracking. Results of this study showed that abnormal foot position, that supination was not having any significant difference from neutral. Some authors said that there is significant difference in abnormal foot position. The pronation of foot showed significant difference from neutral, that in VMO is no significant different ( $p$ value 0.25 ) but in VL showed significant difference (p-value 0.0099). This may caused because of internal rotation of tibia there may be stretching of VL was present according to optimal length tension relationship, the VL activity was more. Based on the results obtained from this study showed that pronated foot may have effect on quadriceps muscle. This information is useful that patients with patellofemoral pain, the foot assessment (or) screening is necessary, reported a significant difference in pain, because using a foot orthotic to treat patellofemoral pain in patients who had pronated feet. Evaluation of other structural foot deformities such as forefoot posture may also be useful in providing information regarding pathomechanics of the patellofemoral joint. Rear foot varus may be a factor in contributing to patellofemoral pain and should be considered in the biomechanical evaluation of the lower extremity. To limit pronation, it is common practice to prescribe in-shoe foot orthoses with a varus correction. This is presumed to reduce internal rotation of tibia and to have some effect on the internal-external rotation patterns of the tibiofemoral joint with alleviation of stresses on the lateral aspect of the knee and improvement of the tracking of patella.

\section{CONCLUSION}

The VMO and VL activity shows significant difference in the pronated foot weight bearing position compared to the neutral and supinated foot. Therefore the null hypothesis was rejected. Performing the maximum voluntary isometric contractions of VMO and VL with pronated foot elicited significantly higher EMG activity compared to Neutral or supinated weight bearing positions of foot. Several authors suggested that patellofemoral pain may caused by abnormal foot positions. The results have shown very slight significant difference EMG activity while performing exercises with pronated foot. The results of this study showed that pronated foot may have effect on quadriceps muscles this information is useful to assess the foot positions in patients with patellofemoral pain. The results of this study also suggested that for patellofemoral pain which is caused by pronated foot can be treating by using the soft foot orthoses. Several studies also suggested that soft foot orthoses was helpful to treat the patellofemoral pain syndrome. The use of foot orthoses may have effect on to correct a pronated foot for patients with patellofemoral pain syndrome. 


\section{REFERENCES}

1. You-Jou Hung et al. Effect of foot position on Electromyographic activity of Vastus Medialis Oblique and Vastus Lateralis during lower extremity weight bearing activities. JOSPT.1999; 29(2): 93-105.

2. Powers $\mathrm{CM}$ et al. Comparison of foot pronation and lower extremity rotation in persons with and without patellofemoral pain. Foot Ankle Int. 2002; 23(7): 634-40.

3. Terry G. The anatomy of the extensor mechanism. Clinics in Sports Medicine.1989; 8(2):163-177.

4. Moffat DB. Anatomy and physiology for physiotherapists. Second edition; 1997.

5. Dianne Zakaria et al. Preferential activation of the Vastus Medialis Oblique, Vastus Lateralis, and Hip Adductor Muscles During Isometric exercises in Females. JOSPT.1997; 26(1): 23-28.

6. Joseph. F. Signorile et al. The effect of knee and foot position on the Electromyographical activity of the superficial quadriceps. JOSPT. 1995; 22; (1):182-187.

7. David. J. Magee. Orthopaedic physical Assessment. Fourth edition, 2002.

8. M.A. Lafortune et al. Foot Inversion - Eversion and knee kinematics during walking. J orthop Res.1993; 13(3): 412-419.

9. Reed Ferber et al. Effect of foot orthotics on rearfoot and tibia joint coupling patterns and variability. Journal of Biomechanics.2005; 38(3):477-83.

10. Christopher M. Powers et al. Rear foot posture in subjects with patellofemoral pain. JOSPT.1995;22(4):155-160.

11. Janice J Eng et al. Evaluation of soft foot orthotics in the treatment of patellofemoral pain syndrome. Physical Therapy. 1993; 73(2): 62-68.

12. Holly M. Rose et al. Acute orthotic intervention does not affect muscular response times and activation patterns at the knee. J Athl Train. 2002; 37(2):133-140.

13. Perry et al. EMG - force relationship in skeletal muscle. Crit Rev Biomed Eng. 1981; 7(1):1-22.

14. Tepperman PS. Effect of ankle position on isometric quadriceps strengthening. Am J Phys Med. 1986; 65(2): 69-74.

15. Gary. L. Soderberg et al. Electromyographic Analysis of knee exercises in healthy subjects and in patients with knee pathologies. Physical Therapy. 1987; 67 (11):1691-97.

16. Klingman RE et al. The effect of subtalar joint posting on patellar glide position in subjects with excessive rear foot pronation. JOSPT. 1997; 25(3):185-91.

17. George J Davies et al. Selective activation of the Vastus Medialis Oblique: What does the literature really tell us? Physiotherapy Canada .2001; 53:100-115.

\section{How to cite this article:}

Sreekar Kumar Reddy .R, B. Siva Kumar, N. Vamsidhar, G. Haribabu. ELECTROMYOGRAPHIC ACTIVITY OF THE VASTUS MEDIALIS OBLIQUE AND VASTUS LATERALIS DURING MAXIMUM VOLUNTARY ISOMETRICS IN DIFFERENT WEIGHT BEARING POSITIONS OF THE FOOT. Int J Physiother.2014; 1(3):120-126. 